\title{
Postoperative Exacerbation of Oxaliplatin-induced Neurotoxicity in Gastrointestinal Cancers: A Case Series
}

\author{
AMALIA GONZALEZ ${ }^{*}$, EVAN J. WALKER ${ }^{2,3^{*}}$, KATHERINE VAN LOON ${ }^{2,3}$, \\ PELIN CINAR ${ }^{2,3}$ and CHLOE E. ATREYA ${ }^{2,3}$ \\ ${ }^{1}$ School of Medicine, University of California San Francisco, San Francisco, CA, U.S.A.; \\ ${ }^{2}$ Department of Medicine, Division of Hematology and Oncology, \\ University of California San Francisco, San Francisco, CA, U.S.A.; \\ ${ }^{3}$ UCSF Helen Diller Family Comprehensive Cancer Center, San Francisco, CA, U.S.A.
}

\begin{abstract}
Background/Aim: Oxaliplatin-induced neurotoxicity (OIN) can be severe and dose-limiting with clinically significant symptoms that persist for years. Few published reports have described postoperative exacerbation of OIN and more longitudinal data are needed to better characterize the phenomenon. Patients and Methods: We identified 13 patients diagnosed with colon $(n=7)$, rectal $(n=4)$ or pancreatic $(n=2)$ cancer who experienced postoperative OIN exacerbation at our medical center. Charts were reviewed for demographic and clinical data regarding OIN. Results: OIN exacerbation was documented 0.5-7.0 months after the first surgery following oxaliplatin exposure, with a median duration of 10.6 months (range $=1.4-86.1$ months). OIN exacerbation persisted in 3/13 patients at last follow-up, and improved to pre-operative levels in 6/13 patients (with complete resolution in 4/13) within a median of 3.6 months from initial exacerbation. Conclusion: Given the widespread use of oxaliplatin in neoadjuvant and first-line treatment for gastrointestinal cancers, further study is warranted to prospectively and systematically define risks for postoperative OIN exacerbation.
\end{abstract}

Oxaliplatin is used to treat colorectal cancer and other gastrointestinal malignancies in the neoadjuvant, adjuvant, and metastatic settings (1-6). One of its predominant and often dose-limiting toxicities is peripheral sensory

This article is freely accessible online.

*These Authors contributed equally to this work.

Correspondence to: Chloe E. Atreya University of California, 550 16th Street, 6th Floor, Box 3211, San Francisco, CA 94158, U.S.A. Tel: +1 4153539888, Fax: +1 4153539931, e-mail: chloe.atreya@ucsf.edu

Key Words: Chemotherapy-induced neurotoxicity, oxaliplatin, colorectal cancer, gastrointestinal cancer. neuropathy. Acute oxaliplatin-induced neurotoxicity (OIN) manifests as paresthesias of the extremities and/or laryngopharynx and is typically associated with cold-induced dysesthesia (7-9). Chronic OIN is due to cumulative oxaliplatin dose and can result in permanent functional limitation, including impaired fine motor skills, changes in proprioception, increased fall risk, and pain. Unlike acute OIN, chronic OIN does not resolve between treatment cycles and may become permanent (10).

There is wide variation in the clinical course of OIN, but studies have consistently shown almost all patients will experience at least mild acute neuropathy starting with the first treatment cycle $(1,11,12)$. Dose-limiting oxaliplatin-induced sensory neuropathy occurs at cumulative doses between 667 $810 \mathrm{mg} / \mathrm{m}^{2}$ (7-9 cycles) $(10,13,14)$. Though risk estimates vary considerably, incidence of severe (Common Terminology Criteria for Adverse Events (CTCAE) Grade 3+) chronic neuropathy may be up to $50 \%$ depending on treatment duration (15). Hyper-acute peripheral neuropathy, defined as upper extremity and laryngopharyngeal dysesthesia within 24 hours of the first cycle of chemotherapy, may be one clinical predictor of persistent OIN (16). Other associated factors include duration and intensity of symptoms after six treatment cycles, body surface area (BSA), and concomitant use of bevacizumab, while factors such as age, sex, performance status, comorbid diabetes, and prior treatment history do not seem to be associated (17, 18). Although one longitudinal study found no clinically significant increase in neurotoxicity relative to baseline after a seven-year follow up period, multiple others have documented persistence of chronic OIN for years after treatment (19-21).

Recent data from the International Duration Evaluation of Adjuvant Chemotherapy (IDEA) study, designed to explore non-inferiority of shorter adjuvant treatment ( 3 vs. 6 months) with leucovorin, fluorouracil, and oxaliplatin (FOLFOX) or capecitabine and oxaliplatin (CapeOX) in stage III colon cancer, further support the association between cumulative oxaliplatin dose and OIN (22). In this analysis of six 
Table I. Patient characteristics.

\begin{tabular}{|c|c|c|c|c|c|c|c|c|}
\hline $\begin{array}{l}\text { Patient } \\
\text { ID }\end{array}$ & Gender & Age $^{1}$ & Race & Ethnicity & $\begin{array}{l}\text { Primary } \\
\text { cancer }\end{array}$ & $\begin{array}{l}\text { Tumor } \\
\text { location }\end{array}$ & $\begin{array}{c}\text { Tumor } \\
\text { differentiation }{ }^{2}\end{array}$ & $\begin{array}{l}\text { AJCC } \\
\text { stage }\end{array}$ \\
\hline 1 & M & 33 & White & Non-Hispanic & Colon & Sigmoid colon & Moderately differentiated & ypT2N1bM1 \\
\hline 2 & $\mathrm{~F}$ & 46 & White & Non-Hispanic & Colon & Sigmoid colon & Well differentiated & $\mathrm{TxNxM}^{3}$ \\
\hline 3 & M & 53 & Other & Hispanic & Colon & Descending/sigmoid colon & Moderately differentiated & урT3N0M1 \\
\hline 4 & $\mathrm{~F}$ & 58 & $\begin{array}{l}\text { American Indian/ } \\
\text { Alaska Native }\end{array}$ & Hispanic & Colon & Sigmoid colon & Moderately differentiated & pT4aN1aM0 \\
\hline 5 & $\mathrm{~F}$ & 47 & White & Non-Hispanic & Colon & Distal sigmoid colon & Moderately differentiated & pT3N1aM0 \\
\hline 6 & $\mathrm{~F}$ & 50 & White & Non-Hispanic & Colon & Sigmoid colon & Moderately differentiated & pT4aNOM0 \\
\hline 7 & $\mathrm{M}$ & 41 & Black & Non-Hispanic & Colon & Sigmoid colon & Poorly differentiated & pT3N0M1 \\
\hline 8 & $\mathrm{~F}$ & 61 & White & Non-Hispanic & Rectal & Distal rectum & Poorly differentiated & pT2NOM0 \\
\hline 9 & M & 47 & White & Non-Hispanic & Rectal & Distal rectum & Well differentiated & урT2N0M0 \\
\hline 10 & M & 46 & White & Non-Hispanic & Rectal & Rectosigmoid junction & Well-moderately differentiated & T3aN1M1 \\
\hline 11 & M & 51 & White & Hispanic & Rectal & Distal rectum & Moderately differentiated & uT2N1M0 \\
\hline 12 & M & 57 & Other & Non-Hispanic & Pancreatic & Pancreatic head & Well differentiated & ypT3N1M0 \\
\hline 13 & $\mathrm{~F}$ & 60 & White & Non-Hispanic & Pancreatic & Pancreatic head & Moderately-poorly differentiated & ypT3N1M0 \\
\hline
\end{tabular}

${ }^{1}$ At diagnosis; ${ }^{2}$ All cancers are adenocarcinoma; ${ }^{3}$ No stage documented, extensive metastatic disease present at diagnosis. AJCC: American Joint Committee on Cancer.

randomized phase 3 trials encompassing 12,834 patients, neuropathy was the most common indication for dose reduction. Further, significantly less grade 3-4 peripheral sensory neuropathy was reported in the three-month treatment arm compared to the six-month treatment arm. In a sub-analysis from one study group, this discrepancy was found to persist for the entire seven-year study period.

In light of these findings, it is important to characterize the clinical patterns of OIN and understand factors that may impact its duration and severity (11). One hypothesis is that anesthesia exposure leads to OIN exacerbation. While the mechanism is not completely understood, it has been proposed that OIN exacerbation may be related to a redistribution of intra-erythrocytic oxaliplatin metabolites in the setting of perioperative hemolysis (23). This is supported by the finding that cumulative OIN may correlate with intra-erythrocytic drug concentration, as oxaliplatin accumulates within erythrocytes more so than other platinum agents $(10,24)$.

One prospective case series of patients with primary colon or adrenal tumors who received neoadjuvant oxaliplatincontaining regimens showed postoperative OIN exacerbation in seven of 12 patients (23). Another report described three patients with metastatic colorectal cancer who experienced mild transient neurotoxicity after initial treatment with an oxaliplatin-containing regimen and later reported exacerbation or functional impairment within two weeks after resection of metastases, with symptoms persisting up to one year following surgery (25). One patient with hepatocellular carcinoma who received neoadjuvant sorafenib, gemcitabine, and oxaliplatin described escalation from CTCAE Grade 1 to Grade 2 neurotoxicity following liver resection, which persisted and ultimately led to oxaliplatin discontinuation (26).
Given the large number of patients with gastrointestinal cancers who are treated with platinum-based regimens in the perioperative setting, understanding the relationship between surgery and OIN exacerbation is important. Specifically for locally advanced rectal cancer, total neoadjuvant therapy with FOLFOX has been added to the National Comprehensive Cancer Network (NCCN) Guidelines and has been adopted as a standard practice $(27,28)$. Among patients with borderline resectable pancreatic cancer, neoadjuvant therapy with oxaliplatin-containing chemotherapy regimens is leading to improved surgical outcomes (29-31). Data also suggest improvement in outcomes with neoadjuvant oxaliplatincontaining therapy in adenocarcinoma of the stomach and esophagogastric junction (32).

In this case series, we aim to describe and better characterize postoperative OIN exacerbation in patients with cancers of the colon, rectum, or pancreas.

\section{Patients and Methods}

We identified adult patients with primary gastrointestinal cancers who received neoadjuvant oxaliplatin and experienced new or exacerbated postoperative OIN through provider recall. Patients were treated between 2010-2017 in the Gastrointestinal Oncology Clinic at the University of California San Francisco (UCSF) Helen Diller Family Comprehensive Cancer Center. All patients received at least one dose of oxaliplatin prior to undergoing a surgical procedure. A structured retrospective chart review was generated following approval by the UCSF Institutional Review Board (study \#17-21995).

Past medical history of each patient was reviewed to assess for conditions that could predispose to neuropathy (e.g., diabetes). Cumulative total oxaliplatin was calculated based on the patient's 
Table II. Oxaliplatin treatment regimens.

\begin{tabular}{|c|c|c|c|c|c|c|c|c|}
\hline $\begin{array}{l}\text { Patient } \\
\text { ID }\end{array}$ & $\begin{array}{l}\text { Time to } \\
\text { OX (mo })^{1}\end{array}$ & $\begin{array}{l}\text { Prior } \\
\text { regimens }\end{array}$ & $\begin{array}{l}\mathrm{OX} \\
\text { regimens }\end{array}$ & $\begin{array}{c}\mathrm{OX} \\
\text { cycles }^{2}\end{array}$ & $\begin{array}{c}\text { OX dose \& } \\
\text { schedule }\left(\mathrm{mg} / \mathrm{m}^{2}\right)\end{array}$ & $\begin{array}{l}\text { OX dose reductions; } \\
\text { Indication }\end{array}$ & $\begin{array}{c}\text { Cumulative OX } \\
\text { dose }\left(\mathrm{mg} / \mathrm{m}^{2}\right)\end{array}$ & $\begin{array}{c}\text { Treatment } \\
\text { duration }(\mathrm{mo})\end{array}$ \\
\hline 1 & 0.7 & - & FOLFOX+Cetux & 6 & $85 \mathrm{Q} 2 \mathrm{~W}$ & No & 536 & 2.6 \\
\hline 2 & 0.5 & - & FOLFOX+Bev & 10 & $85 \mathrm{Q} 2 \mathrm{~W}$ & $\begin{array}{c}30 \% \text { beginning } \mathrm{C} 9 \\
\text { neuropathy }\end{array}$ & 820 & 4.6 \\
\hline 3 & 0.7 & - & CapeOX+Bev & 10 & $130 \mathrm{Q} 3 \mathrm{~W}$ & No & 1300 & 6.4 \\
\hline 4 & 13.3 & - & CapeOX+Bev & 8 & $97.5 \mathrm{Q} 3 \mathrm{~W}$ & $\begin{array}{l}25 \% \text { beginning } \mathrm{C} 1 ; \\
\text { patient preference }\end{array}$ & 776 & 4.9 \\
\hline 5 & 13.7 & FOLFIRI & FOLFOXIRI+Bev & 6 & $85 \mathrm{Q} 2 \mathrm{~W}$ & No & 502 & 2.8 \\
\hline 6 & 1.4 & - & FOLFOX & 9 & $85 \mathrm{Q} 2 \mathrm{~W}$ & $\begin{array}{l}20 \% \text { beginning } \mathrm{C} 9 \\
\text { thrombocytopenia }\end{array}$ & 766 & 3.7 \\
\hline 7 & 1.2 & - & $\begin{array}{l}\text { CapeOX } \\
\text { FOLFOX }\end{array}$ & $\begin{array}{l}2 \\
2\end{array}$ & $\begin{array}{l}130 \mathrm{Q} 3 \mathrm{~W} \\
85 \mathrm{Q} 2 \mathrm{~W}\end{array}$ & No & 428 & $\begin{array}{l}0.6 \\
0.5\end{array}$ \\
\hline 8 & 4.2 & $\mathrm{~F}+\mathrm{XRT}$ & FOLFOX & 4 & $85 \mathrm{Q} 2 \mathrm{~W}$ & $\begin{array}{c}\% \text { unknown beginning } \mathrm{C} 3 ; \\
\text { neutropenia }\end{array}$ & 3413 & 2.1 \\
\hline 9 & 3.6 & $\mathrm{~F}+\mathrm{XRT}$ & $\begin{array}{l}\text { FOLFOX } \\
\text { FOLFOX }\end{array}$ & $\begin{array}{l}6 \\
2\end{array}$ & $\begin{array}{l}85 \mathrm{Q} 2 \mathrm{~W} \\
85 \mathrm{Q} 2 \mathrm{~W}\end{array}$ & No & 687 & $\begin{array}{l}2.4 \\
0.4\end{array}$ \\
\hline 10 & 0.9 & - & $\begin{array}{l}\text { FOLFOX } \\
\text { CapeOX }\end{array}$ & $\begin{array}{c}10 \\
3\end{array}$ & $\begin{array}{l}85 \mathrm{Q} 2 \mathrm{~W} \\
130 \mathrm{Q} 3 \mathrm{~W}\end{array}$ & No & 1228 & $\begin{array}{l}6.2 \\
1.4\end{array}$ \\
\hline 11 & 4.2 & Cape+XRT & FOLFOX & 8 & $85 \mathrm{Q} 2 \mathrm{~W}$ & No & 664 & 4.1 \\
\hline 12 & 1.8 & - & FOLFIRINOX & 18 & $85 \mathrm{Q} 2 \mathrm{~W}$ & No & 1523 & 9.0 \\
\hline 13 & 1.9 & - & FOLFIRINOX & 12 & $85 \mathrm{Q} 2 \mathrm{~W}$ & $\begin{array}{l}20 \% \text { beginning } \mathrm{C} 8 \\
\text { thrombocytopenia }\end{array}$ & 891 & 6.8 \\
\hline Median & 1.6 & & & 7 & & & 766 & 4.1 \\
\hline Range & $0.5-13.7$ & & & $2-18$ & & & $341-1523$ & $1.1-9.0$ \\
\hline
\end{tabular}

${ }^{1}$ Relative to date of diagnosis; ${ }^{2}$ Total number of cycles; ${ }^{3}$ Cumulative dose estimated based on starting regimen dose. OX: oxaliplatin; FOLFOX: 5fluorouracil, folinic acid, and oxaliplatin; Cetux: cetuximab; Bev: bevacizumab; CapeOX: capecitabine and oxaliplatin; FOLFIRI: 5-fluorouracil, folinic acid, and irinotecan; FOLFOXIRI: 5-fluorouracil, folinic acid, oxaliplatin and irinotecan; F+XRT: 5- fluorouracil and radiation therapy; Cape+XRT: capecitabine and radiation therapy; FOLFIRINOX: 5-fluorouracil, folinic acid, irinotecan and oxaliplatin.

BSA (using height and weight recorded immediately prior to treatment initiation), dose in milligrams $(\mathrm{mg})$, and number of treatment cycles, adjusting for dose reductions as appropriate. Data on neuropathy was abstracted from review of clinic notes. OIN exacerbation was defined as worsened neuropathy (numbness, tingling, pain, and/or temperature sensitivity) from baseline, as described by providers based on qualitative patient report. Resolution of OIN exacerbation was assessed in the same manner.

\section{Results}

Demographic and clinical characteristics of the patients are summarized in Table I. Median age at diagnosis was 50 years (range=33-61 years). None of the 13 patients reported any signs or symptoms of neuropathy, nor comorbid conditions predisposing to neuropathy, prior to initiating chemotherapy with oxaliplatin. Seven patients were treated for colon adenocarcinoma, four for rectal adenocarcinoma, and two for pancreatic adenocarcinoma. The demographic characteristics were representative of patients seen in the Gastrointestinal Oncology practice at our institution (54\% male and $62 \%$ non-Hispanic white).
Oxaliplatin was administered as a component of first- or second-line chemotherapy to all patients. Table II presents additional information regarding each individual regimen. In colon cancer patients $(n=7)$, oxaliplatin was administered before primary tumor resection in two cases, with the remaining five receiving oxaliplatin prior to resection of metastases. All rectal cancer patients $(n=4)$ and pancreatic cancer patients $(n=2)$ received oxaliplatin before resection of the primary tumor. Median total cumulative oxaliplatin dose was $766 \mathrm{mg} / \mathrm{m}^{2}$ (range $=341-1523 \mathrm{mg} / \mathrm{m}^{2}$ ) administered over a median period of 4.1 months (range=1.1-9.0 months), corresponding to a median of 7 treatment cycles (range=2-18 cycles). Of the 13 patients, five received dose reduction of oxaliplatin due to neuropathy and/or cytopenia. Almost all (12/13) patients developed stable or progressive OIN during the course of their treatment, while one developed neuropathy after completion of oxaliplatin and a subsequent surgery. There was an average interval of 3.9 months (range=0 $3-25.8$ months) between the final oxaliplatin dose and surgery. Total duration of symptoms varied, but $12 / 13$ patients had reported improvement in neuropathy prior to surgery. While all 13 patients developed OIN exacerbations after surgery, 7/13 


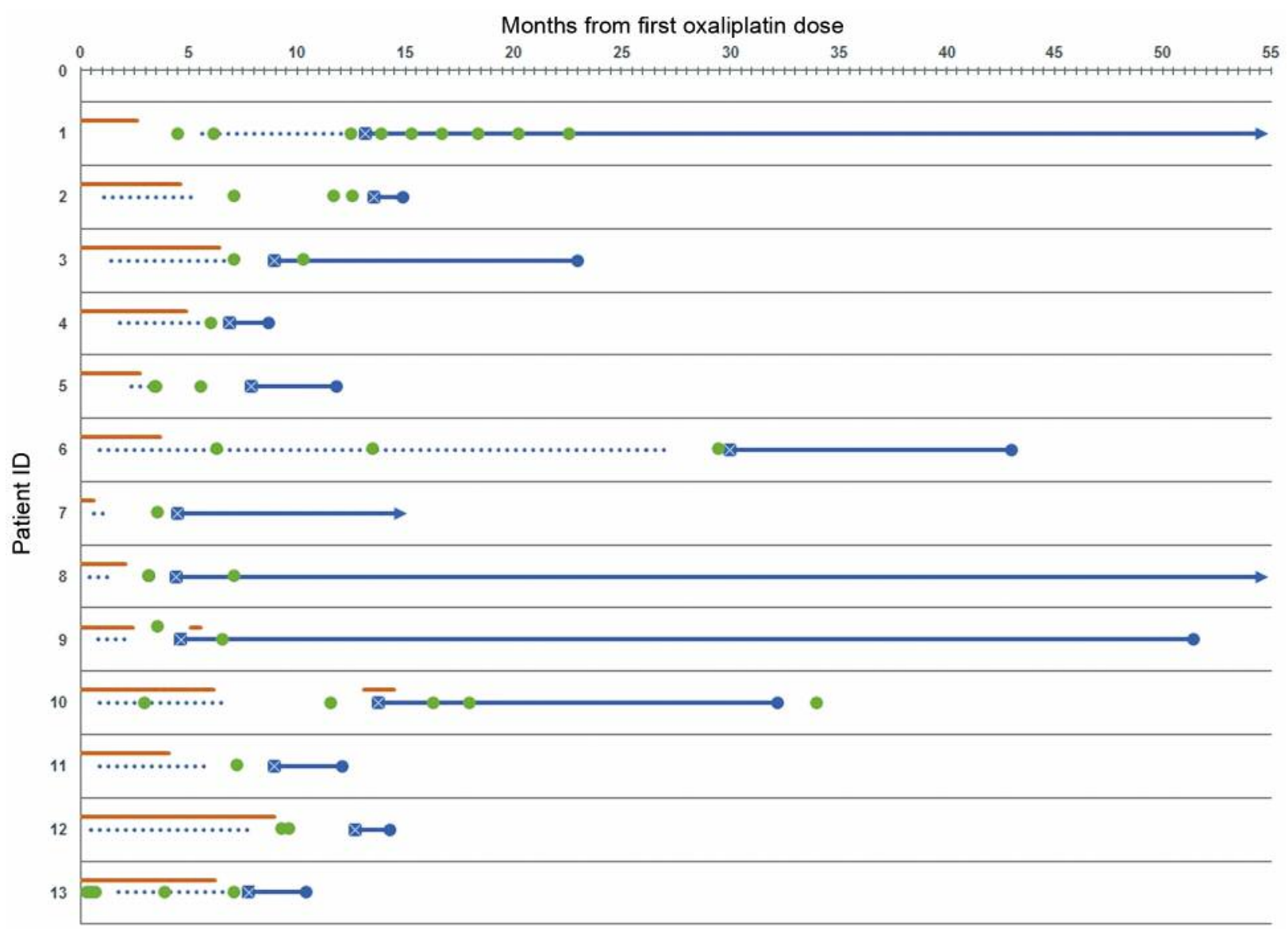

Figure 1. Time course of oxaliplatin-induced neuropathy development and exacerbation (in months) for each patient, normalized to the time of first oxaliplatin dose. Oxaliplatin treatment duration is presented by orange lines. Surgical events are presented by green dots. Neuropathy is presented by blue lines (arrows indicate ongoing neuropathy at time of last follow-up), dotted when experienced prior to the first documented report of exacerbation (blue box).

patients underwent multiple procedures under anesthesia prior to OIN exacerbation. Figure 1 shows the clinical time course of neuropathy relative to procedures performed under anesthesia for each patient, normalized relative to first oxaliplatin dose.

The median follow-up time was 10.7 months from the date of OIN exacerbation. Significant variation in the course and severity of OIN exacerbation was observed. OIN exacerbation was first documented between 0.5 and 7.0 months after surgery, with a median duration of 10.6 months (range $=1.4$ to $>86.1$ months). At the time of last follow-up, $23 \%(3 / 13)$ of patients reported ongoing OIN exacerbations. OIN improved to pre-operative levels in $46 \%(6 / 13)$ of patients, with complete resolution in $31 \%$ (4/13). For patients with localizing details recorded, predominant sites of neuropathy included feet/soles $(42 \%, 5 / 12)$, bilateral distal upper/lower extremities $(42 \%, 5 / 12)$, and hands/fingertips $(16 \%, 2 / 12)$. Formal neuropathy grade was not routinely documented in the medical record. While patients described intense discomfort with symptom flares, no severe functional limitations or falls were documented.

\section{Discussion}

The use of oxaliplatin in the neoadjuvant setting is increasingly common in clinical practice $(30,31)$. As such, understanding the effects of anesthesia exposure on OIN is of particular importance, especially given the possible functional implications of chronic toxicity. In this case series, we present a group of 13 patients who reported aggravation of pre-existing OIN following anesthesia exposure. The variability in demographics, cancer characteristics and oxaliplatin dosing that we report suggests postoperative OIN exacerbation has the potential to affect a broad set of patients who receive oxaliplatin in the neoadjuvant setting. 
Options for treatment of OIN are limited, making it difficult to control exacerbations of symptoms following surgery. Acupuncture has been anecdotally shown to be effective for neuropathy caused by other chemotherapies, but this has not been studied extensively $(33,34)$. Despite conflicting results from small retrospective studies, calcium and magnesium infusions have been shown, in a phase III randomized study, to have no significant effect in reducing OIN (35, 36). While duloxetine, a serotonin and norepinephrine reuptake inhibitor (SNRI), has been shown to be effective in reducing pain for patients with painful chemotherapy-induced neuropathy, its effect in non-painful neuropathy is not well characterized (37). More broadly, pharmacotherapies traditionally used for neuropathy, such as gabapentin, have not performed well in randomized trials in the setting of chemotherapy-induced symptoms (38). Given the dearth of treatment options, management of cancer patients whose neuropathy worsens postoperatively is challenging. As such, there is a need to better understand this clinical entity to enable providers to identify those at high risk for exacerbation of OIN and to better counsel patients on the possible risks of anesthesia exposure.

To our knowledge, this is the largest case series describing postoperative OIN exacerbation. Several limitations of this exploratory study, and opportunities for prospective investigation, should be acknowledged. Given the retrospective nature of the study, we were unable to ascertain the specific duration of anesthesia exposure. We do demonstrate a temporal association between surgery and OIN exacerbation, however, the question of whether there is a dose-response relationship between anesthetic exposure and OIN severity warrants future prospective studies. The retrospective nature of the study also precluded correlative laboratory or radiographic measurements. For example, one previous study reporting OIN exacerbation examined intraerythrocytic and unbound plasma oxaliplatin levels in the pre- and post-operative settings, as well as unconjugated bilirubin. Another showed evidence of redistribution of oxaliplatin metabolites from erythrocytes to plasma (23). Finally, recent evidence suggests an association between psoas muscle cross-sectional area, a marker of nutritional status, and risk of OIN (39). While we did not have these data in our patient cohort, future studies should examine putative biomarkers for OIN. Finally, recall bias is a possibility in a retrospective study such as ours, though structured chart review was completed to identify any mention of OIN severity in the medical record. Future prospective study of postoperative OIN exacerbation will require regular check-ins (possibly using digital health technology) to pinpoint the onset and resolution of OIN and administration of validated questionnaires to score symptom severity including impact on activities of daily living and quality of life $(21,40)$.

\section{Conclusion}

Postoperative OIN exacerbation is experienced by a diverse group of gastrointestinal cancer patients. Our data suggest this phenomenon warrants future study. Future studies should aim to identify prospective biomarkers for exacerbation to determine which patients are at highest risk and to provide perioperative patient counseling.

\section{Conflicts of Interest}

The Authors disclose no conflicts of interest pertaining to this manuscript.

\section{Authors' Contributions}

AG: Conceived and designed the analysis, collected data, performed analysis, contributed to manuscript; EW: Conceived and designed the analysis, collected data, performed analysis, contributed to manuscript; KVL: Contributed data, contributed to manuscript; PC: Conceived and designed the analysis, contributed data, contributed to manuscript; CA: Conceived and designed the analysis, contributed data, contributed to manuscript.

\section{References}

1 André T, Boni C, Mounedji-Boudiaf L, Navarro M, Tabernero J, Hickish T, Topham C, Zaninelli M, Clingan P, Bridgewater J, Tabah-Fisch I, de Gramont A and Multicenter International Study of Oxaliplatin/5-Fluorouracil/Leucovorin in the Adjuvant Treatment of Colon Cancer (MOSAIC) Investigators: Oxaliplatin, fluorouracil, and leucovorin as adjuvant treatment for colon cancer. N Engl J Med 350: 2343-2351, 2004. PMID: 15175436. DOI: 10.1056/NEJMoa032709

2 Goldberg RM, Sargent DJ, Morton RF, Fuchs CS, Ramanathan RK, Williamson SK, Findlay BP, Pitot HC and Alberts SR: A randomized controlled trial of fluorouracil plus leucovorin, irinotecan, and oxaliplatin combinations in patients with previously untreated metastatic colorectal cancer. J Clin Oncol 22: 23-30, 2004. PMID: 14665611. DOI: 10.1200/JCO.2004.09.046

3 Louafi S, Boige V, Ducreux M, Bonyhay L, Mansourbakht T, de Baere T, Asnacios A, Hannoun L and Poynard TTJ: Gemcitabine plus oxaliplatin (GEMOX) in patients with advanced hepatocellular carcinoma (HCC): results of a phase II study. Cancer 109(7): 1384-1390, 2007. PMID: 17330837. DOI: $10.1002 /$ cncr.22532

4 Andre T, Tournigand C, Rosmorduc O, Provent S, MaindraultGoebel F, Avenin D, Selle F, Paye F, Hannoun L, Houry S, Gayet B, Lotz JP, De Gramont A and Louvet C: Gemcitabine combined with oxaliplatin (GEMOX) in advanced biliary tract adenocarcinoma: a GERCOR study. Ann Oncol 15: 1339-1343, 2004. PMID: 15319238. DOI: 10.1093/annonc/mdh351

5 Cunningham D, Starling N, Rao S, Iveson T, Nicolson M, Coxon F, Middleton G, Daniel F, Oates J and Norman AR: Capecitabine and oxaliplatin for advanced esophagogastric cancer. N Engl J Med 358: 36-46, 2008. PMID: 18172173. DOI: $10.1056 /$ NEJMoa073149 
6 Conroy T, Desseigne F, Ychou M, Bouche O, Guimbaud R, Gourgou-bourgade $\mathrm{S}$, de la Fouchardière $\mathrm{C}$, Bennouna J, Bachet J-B, Assenat E, Chauffert B, Michel P, Montoto-Grillot C and Ducreux M: FOLFIRINOX versus gemcitabine for metastatic pancreatic cancer. N Engl J Med 364: 1817-1825, 2011. PMID: 21561347. DOI: 10.1056/NEJMoa1011923

7 Pasetto LM, D'Andrea MR, Rossi E and Monfardini S: Oxaliplatin-related neurotoxicity: How and why? Crit Rev Oncol Hematol 59: 159-168, 2006. PMID: 16806962. DOI: 10.1016/j.critrevonc.2006.01.001

8 Pachman DR, Qin R, Seisler D, Smith EML, Kaggal S, Novotny P, Ruddy KJ, Lafky JM, Ta LE, Beutler AS, Wagner-Johnston ND, Staff NP, Grothey A, Dougherty PM, Cavaletti G and Loprinzi CL: Comparison of oxaliplatin and paclitaxel-induced neuropathy (Alliance A151505). Support Care Cancer 24: 5059-5068, 2016. PMID: 27534963. DOI: 10.1007/s00520-016-3373-1

9 Argyriou AA, Cavaletti G, Briani C, Velasco R, Bruna J, Campagnolo M, Alberti P, Bergamo F, Cortinovis D, Cazzaniga M, Santos C, Papadimitriou K and Kalofonos HP: Clinical pattern and associations of oxaliplatin acute neurotoxicity: A prospective study in 170 patients with colorectal cancer. Cancer 119: 438-444, 2013. PMID: 22786764. DOI: 10.1002/cncr.27732

10 Cersosimo RJ: Oxaliplatin-associated neuropathy: A review. Ann Pharmacother 39: 128-135, 2005. PMID: 15590869. DOI: 10.1345/aph.1E319

11 Pachman DR, Qin R, Seisler DK, Smith EML, Beutler AS, Ta LE, Lafky JM, Wagner-Johnston ND, Ruddy KJ, Dakhil S, Staff NP, Grothey A and Loprinzi CL: Clinical course of oxaliplatininduced neuropathy: Results from the randomized phase III trial N08CB (Alliance). J Clin Oncol 33: 3416-3422, 2015. PMID: 26282635. DOI: $10.1200 / \mathrm{JCO} .2014 .58 .8533$

12 Leonard GD, Wright M a, Quinn MG, Fioravanti S, Harold N, Schuler B, Thomas RR and Grem JL: Survey of oxaliplatinassociated neurotoxicity using an interview-based questionnaire in patients with metastatic colorectal cancer. BMC Cancer 5: 116, 2005. PMID: 16168057. DOI: 10.1186/1471-2407-5-116

13 André T, Boni C, Navarro M, Tabernero J, Hickish T, Topham C, Bonetti A, Clingan P, Bridgewater J, Rivera F and De Gramont A: Improved overall survival with oxaliplatin, fluorouracil, and leucovorin as adjuvant treatment in stage II or III colon cancer in the MOSAIC trial. J Clin Oncol 27: 31093116, 2009. PMID: 19451431. DOI: 10.1200/JCO.2008.20.6771

14 Kuebler JP, Wieand HS, O'Connell MJ, Smith RE, Colangelo LH, Yothers G, Petrelli NJ, Findlay MP, Seay TE, Atkins JN, Zapas JL, Goodwin JW, Fehrenbacher L, Ramanathan RK, Conley BA, Flynn PJ, Soori G, Colman LK, Levine EA, Lanier KS and Wolmark N: Oxaliplatin combined with weekly bolus fluorouracil and leucovorin as surgical adjuvant chemotherapy for stage II and III colon cancer: results from NSABP C-07. J Clin Oncol 25: 2198-2204, 2007. PMID: 17470851. DOI: 10.1200/JCO.2006.08.2974

15 De Gramont A, Figer A, Seymour M, Homerin M, Hmissi A, Cassidy J, Boni C, Cortes-Funes H, Cervantes A, Freyer G, Papamichael D, Le Bail N, Louvet C, Hendler D, De Braud F, Wilson C, Morvan F and Bonetti A: Leucovorin and fluorouracil with or without oxaliplatin as first-line treatment in advanced colorectal cancer. J Clin Oncol 18: 2938-2947, 2000. PMID: 10944126. DOI: $10.1200 / \mathrm{JCO} .2000 .18 .16 .2938$

16 Tanishima H, Tominaga T, Kimura M, Maeda T, Shirai Y and Horiuchi T: Hyperacute peripheral neuropathy is a predictor of oxaliplatin-induced persistent peripheral neuropathy. Support Care Cancer, 2016. PMID: 27921224. DOI: 10.1007/s00520016-3514-6

17 Pulvers JN and Marx G: Factors associated with the development and severity of oxaliplatin-induced peripheral neuropathy: A systematic review. Asia Pac J Clin Oncol 13: 345355, 2017. PMID: 28653815. DOI: 10.1111/ajco.12694

18 Ramanathan RK, Rothenberg ML, de Gramont A, Tournigand C, Goldberg RM, Gupta S and André T: Incidence and evolution of oxaliplatin-induced peripheral sensory neuropathy in diabetic patients with colorectal cancer: a pooled analysis of three phase III studies. Ann Oncol 21: 754-758, 2010. PMID: 19887466. DOI: $10.1093 /$ annonc/mdp509

19 Kidwell KM, Yothers G, Ganz PA, Land SR, Ko CY, Cecchini RS, Kopec JA and Wolmark N: Long-term neurotoxicity effects of oxaliplatin added to fluorouracil and leucovorin as adjuvant therapy for colon cancer: Results from National Surgical Adjuvant Breast and Bowel Project trials C-07 and LTS-01. Cancer 118: 5614-5622, 2012. PMID: 22569841. DOI: $10.1002 /$ cncr.27593

20 Park SB, Lin CSY, Krishnan A V, Goldstein D, Friedlander ML and Kiernan MC: Long-term neuropathy after oxaliplatin treatment: Challenging the dictum of reversibility. Oncologist 16: 708-716, 2011. PMID: 21478275. DOI: 10.1634/theoncologist.2010-0248

21 Iveson TJ, Kerr RS, Saunders MP, Cassidy J, Hollander NH, Tabernero J, Haydon A, Glimelius B, Harkin A, Allan K, Mcqueen J, Scudder C, Boyd KA, Briggs A, Waterston A, Medley L, Wilson C, Ellis R, Essapen S, Dhadda AS, Harrison M, Falk S, Raouf S, Rees C, Olesen RK, Propper D, Bridgewater J, Azzabi A, Farrugia D, Webb A, Cunningham D, Hickish T, Weaver A, Gollins S, Wasan HS and Paul J: 3 versus 6 months of adjuvant oxaliplatin-fluoropyrimidine combination therapy for colorectal cancer (SCOT): an international, randomised, phase 3, noninferiority trial. Lancet Oncol 19: 562-578, 2018. PMID: 29611518. DOI: $10.1016 / \mathrm{S} 1470-2045(18) 30093-7$

22 Shi Q, Sobrero AF, Shields AF, Yoshino T, Paul J, Taieb J, Sougklakos I, Kerr R, Labianca R, Meyerhardt JA, Bonnetain F, Watanabe T, Boukovinas I, Renfro LA, Grothey A, Niedzwiecki D, Torri V, Andre T, Sargent DJ and Iveson T: Prospective pooled analysis of six phase III trials investigating duration of adjuvant (adjuv) oxaliplatin-based therapy ( $3 \mathrm{vs} .6$ months) for patients (pts) with stage III colon cancer (CC): The IDEA (International Duration Evaluation of Adjuvant chemotherapy) collaboration. J Clin Oncol 35: suppl; abstr LBA1, 2017. DOI: 10.1200/JCO.2017.35.18_suppl.LBA1

23 Gornet JM, Savier E, Lokiec F, Cvitkovic E, Misset JL and Goldwasser F: Exacerbation of oxaliplatin neurosensory toxicity following surgery. Ann Oncol 13: 1315-1318, 2002. PMID: 12181257. DOI: $10.1093 /$ annonc/mdf254

24 Graham MA, Lockwood GF, Greenslade D, Brienza S, Bayssas $\mathrm{M}$ and Gamelin E: Clinical pharmacokinetics of oxaliplatin: A critical review. Clin Cancer Res 6: 1205-1218, 2000. PMID: 10778943.

25 Cournede A, Ries P, Richard K, Guillain A, Dahan L, Grandval P, Pourroy B, Moutardier V, Hardwigsen J, Braguer D and Seitz JF: Oxaliplatin neurotoxicity: a report of three cases with postoperative exacerbation. Gastroenterol Clin Biol 29: 461-464, 2005. PMID: 15864213. DOI: 10.1016/s0399-8320(05)80817-6

26 Williet N, Dubreuil O, Boussaha T, Trouilloud I, Landi B, Housset M, Botti M, Rougier P, Belghiti J and Taieb J: 
Neoadjuvant sorafenib combined with gemcitabine plus oxaliplatin in advanced hepatocellular carcinoma. World J Gastroenterol 17: 2255-2258, 2011. PMID: 21633538. DOI: 10.3748/wjg.v17.i17.2255

27 Cercek A, Roxburgh CSD, Strombom P, Smith JJ, Temple LKF, Nash GM, Guillem JG, Paty PB, Yaeger R, Stadler ZK, Seier K, Gonen M, Segal NH, Reidy DL, Varghese A, Shia J, Vakiani E, Wu AJ, Crane CH, Gollub MJ, Garcia-Aguilar J, Saltz LB and Weiser MR: Adoption of total neoadjuvant therapy for locally advanced rectal cancer. JAMA Oncol 4: e180071-e180071, 2018. PMID: 29566109. DOI: 10.1001/jamaoncol.2018.0071

28 National Comprehensive Cancer Network. Rectal Cancer (Version 1.2019). Available at: https://www.ncen.org/ professionals/physician_gls/pdf/rectal.pdf

29 Kim SS, Nakakura EK, Wang ZJ, Kim GE, Corvera CU, Harris HW, Kirkwood KS, Hirose R, Tempero MA and Ko AH: Preoperative FOLFIRINOX for borderline resectable pancreatic cancer: Is radiation necessary in the modern era of chemotherapy? J Surg Oncol 114: 587-596, 2016. PMID: 27444658. DOI: $10.1002 /$ jso.24375

30 George B, Christians KK, Ritch P, Mahmoud A, Evans DB, Wang H, Tsai S, Kelly T, Thomas JP, Wiebe L and Erickson B: Neoadjuvant FOLFIRINOX for borderline resectable pancreas cancer: A new treatment paradigm? Oncologist 19: 266-274, 2014. PMID: 24569947. DOI: 10.1634/theoncologist.20130273

31 Murphy JE, Wo JY, Ryan DP, Jiang W, Yeap BY, Drapek LC, Blaszkowsky LS, Kwak EL, Allen JN, Clark JW, Faris JE, Zhu AX, Goyal L, Lillemoe KD, DeLaney TF, Fernández-del Castillo C, Ferrone CR and Hong TS: Total neoadjuvant therapy with FOLFIRINOX followed by individualized chemoradiotherapy for borderline resectable pancreatic adenocarcinoma: A Phase 2 Clinical Trial. JAMA Oncol 4: 963-969, 2018. PMID: 29800971. DOI: $10.1001 /$ jamaoncol.2018.0329

32 Al-Batran S, Homann N, Pauligk C et al.: Effect of neoadjuvant chemotherapy followed by surgical resection on survival in patients with limited metastatic gastric or gastroesophageal junction cancer: The aio-flot3 trial. JAMA Oncol 3: 1237-1244, 2017. PMID: 28448662. DOI: 10.1001/jamaoncol.2017.0515

33 Bao T, Goloubeva O, Pelser C, Porter N, Primrose J, Hester L, Sadowska M, Lapidus R, Medeiros M, Lao L, Dorsey SG and Badros AZ: A pilot study of acupuncture in treating bortezomibinduced peripheral neuropathy in patients with multiple myeloma. Integr Cancer Ther 13: 396-404, 2014. PMID: 24867959. DOI: $10.1177 / 1534735414534729$
34 Bao T, Chen P, Piulson L, Li Q, Zhi I, Seidman A and Mao J: Acupuncture for persistent chemotherapy-induced peripheral neuropathy symptoms in solid tumor survivors: A pilot study. In: Society for Integrative Oncology $16^{\text {th }}$ International Conference. New York, NY, 2019. J Altern Complement Med 25, 2019. DOI: 10.1089/acm.2019.29074.abstracts

35 Martyn $\mathrm{K}$ and Petito E: The use of calcium and magnesium to prevent neurotoxicity in patients receiving oxaliplatin. J Adv Pract Oncol 6: 266-270, 2015. PMID: 26557413. DOI: 10.6004/jadpro.2015.6.3.8

36 Loprinzi CL, Qin R, Dakhil SR, Fehrenbacher L, Flynn KA, Atherton P, Seisler D, Qamar R, Lewis GC and Grothey A: Phase III randomized, placebo-controlled, double-blind study of intravenous calcium and magnesium to prevent oxaliplatin-induced sensory neurotoxicity (N08CB/Alliance). J Clin Oncol 32: 9971005, 2014. PMID: 24297951. DOI: 10.1200/JCO.2013.52.0536

37 Smith EML, Pang H, Cirrincione C, Fleishman SB, Paskett ED, Fadul CE, Knox C, Shapiro CL and Gilman P: CALGB 170601: A phase III double blind trial of duloxetine to treat painful chemotherapy-induced peripheral neuropathy (CIPN). J Clin Oncol 30: CRA9013-CRA9013, 2012. PMID: 28140807. DOI: 10.1200/jco.2012.30.18_suppl.cra9013

38 Rao RD, Michalak JC, Sloan JA, Loprinzi CL, Soori GS, Nikcevich DA, Warner DO, Novotny P, Kutteh LA and Wong GY: Efficacy of gabapentin in the management of chemotherapyinduced peripheral neuropathy: A phase 3 randomized, doubleblind, placebo-controlled, crossover trial (N00C3). Cancer 110: 2110-2118, 2007. PMID: 17853395. DOI: $10.1002 /$ cncr.23008

39 Nagata T, Fukuda K, Tamai M, Taniguchi A, Kamiya J, Kambe K, Kamada Y, Iwata G and Yamaoka N: Early neuropathy related to oxaliplatin treatment in advanced and recurrent colorectal cancer. Anticancer Res 39: 1347-1353, 2019. PMID: 30842168. DOI: $10.21873 /$ anticanres.13248

40 Aaronson NK, Ahmedzai S, Bergman B, Bullinger M, Cull A, Duez NJ, Filiberti A, Flechtner H, Fleishman SB and de Haes JC: The European Organization for Research and Treatment of Cancer QLQ-C30: A quality-of-life instrument for use in international clinical trials in oncology. J Natl Cancer Inst 85: 365-376, 1993. PMID: 8433390. DOI: 10.1093/jnci/85.5.365

Received December 27, 2019

Revised January 5, 2020

Accepted January 6, 2020 